\title{
Properties of Gradient Multilayer Nickel Coatings Prepared by Interlaced Jet Electrodeposition
}

\author{
Mingzhi Fan ${ }^{l}$, Lida Shen ${ }^{1, *}$, Mingbo Qiu, Zhanwen Wang, Zongjun Tian \\ College of Mechanical and Electrical Engineering, Nanjing University of Aeronautics and \\ Astronautics, No. 29 Yudao Street, Nanjing, Jiangsu 210016, PR China. \\ ${ }^{1}$ These authors contributed equally to this work. \\ *E-mail: $\underline{\text { dshen@nuaa.edu.cn }}$
}

doi: $10.20964 / 2018.08 .37$

Received: 4 May 2018 / Accepted: 8 June 2018 / Published: 5 July 2018

\begin{abstract}
Jet electrodeposition is an effective method to prepare protective coatings on $\mathrm{NdFeB}$. To improve the performance of interlaced multilayer coatings, layers that changed periodically and gradiently were prepared by changing the current density for even layers. The surface morphology and microstructure of the coatings were characterized by scanning electron microscopy and X-ray diffraction. The adhesion strength, microhardness, and corrosion resistance of the coatings were measured using an automatic scratch tester, a microhardness tester, and an electrochemical workstation. The results indicated that compared with other coatings, the periodic gradient multilayer coatings obtained a flatter surface and a higher corrosion resistance. In addition, the adhesion strength was increased from 9.2N to $21.7 \mathrm{~N}$, and the microhardness was increased from $484 \mathrm{HV}$ to $539 \mathrm{HV}$.
\end{abstract}

Keywords: Sintered NdFeB; Interlaced jet electrodeposition; Periodic gradient multilayer coating; Adhesion strength; Corrosion resistance

\section{FULL TEXT}

(C) 2018 The Authors. Published by ESG (www.electrochemsci.org). This article is an open access article distributed under the terms and conditions of the Creative Commons Attribution license (http://creativecommons.org/licenses/by/4.0/). 